Филология

\title{
Абдраимова Фариза
}

магистрант

Казахского национального университета имени аль-Фараби

Abdraimova Fariza

Graduate Student of the Kazakh National University

Научные руководители:

Жаксылыков Аслан Жамелевич

доктор филологических наук, профессор

Казахский начиональный университет имени аль-Фараби

Жучкова Анна Владимировна кандидат филологических наук, дочент Российский университет дружбы народов

\section{ЭДЬЮТЕЙМЕНТ КАК СОВРЕМЕННАЯ ПЕДАГОГИЧЕСКАЯ ТЕХНОЛОГИЯ ОБУЧЕНИЯ В РАМКАХ ПРЕПОДАВАНИЯ РУССКИХ ВОЛШЕБНЫХ СКАЗОК В ШКОЛЕ
EDUTAINMENT AS A MODERN PEDAGOGICAL TECHNOLOGY OF TEACHING RUSSIAN FAIRY TALES AT SCHOOL

\begin{abstract}
Аннотация. Русская волшебная сказка в рамках школьного обучения представляет собой серьезный объект изучения и осмысления. Ее систематическое изучение имеет важный научно-методический потенциал и для вузовского и для школьного образования. На плане методических интерпретаций в связи с этим объектом можно выявить несколько способов эффективного развития творческого потенциала обучающихся, снятия психоэмочионального напряжения, естественно
\end{abstract}


возникающего в проиессе обучения. Сказка также представляет прекрасный историко-культурный материал, открывающий обучающимся историю страны, культурные традиции и обычаи. Изучение сказки в школе и вузе должно соответствовать не только выработанным методическим принципам, но и несомненным возрастным интересам и потребностям обучающихся, нести нравственно полезную смысловую нагрузку. При этом педагог должен учитывать и то, что в аудитории для ребенка сказка предстает своего рода психологической отдушиной, она дает возможность погрузиться в сказочный мир, развлечься, отдохнуть от учебного прочесса. В зависимости от возраста обучающихся подход к изучению материала может быть различным. Однако, общчим является тот принщип, что изучение сказок неразрывно связано с понятием эдьютеймента, т.е. суммированным опытом игровой методики, которая может быть представлена в различных моделях и форматах. В связи с этим, актуальным является вопрос применения личностноориентированной технологии обучения. В данной статье решается именно эта проблема, проинтерпретированная на материале определенного onbima.

Ключевые слова: эдьютеймент, методика, сказка, гуманизация, подход, урок, прочесс, презентациия.

Summary. The Russian fairy tale within the school education is a major object of case study and comprehension. The systematic study has an important scientific and methodological potential for both university and school education. Only by adherting to the plan of methodological interpretations in relation to this object, it is possible to identify several ways to effectively develop the creative potential of students, to relieve the psycho-emotional stress that naturally occurs in the learning process. The fairy tale also provides great historical and cultural material that opens up the history of the country, cultural traditions and customs. 
The study of fairy tales at school and university should comply with the developed methodological principles but also the undoubted age interests and students needs, contain a moral and useful semantic content. The teacher should draw the attention to the fact that the fairy tale is seen as a psychological relief by children, it gives them the opportunity to dive in the magic world, have fun and take a break from the learning process. The approach to study may be different depending on the age of students. However, the major principle of fairy tales study is inextricably linked with the concept of edutainment, i.e. the combined experience of a game technique that can be presented in various models and formats. In this regard, the issue of applying personality-oriented learning technology is relevant. This article solves the exact problem interpreted on the basis of a certain experience.

Key words: edutainment, methodology, fairy tale, humanization, approach, lesson, process, presentation.

Введение. В процессе современного динамично развивающегося образования необходимо активизировать дидактические способы и приемы, нацеленные на развитие творческих навыков обучающихся. В этом процессе естественна смена приоритетов в обучении, когда, например, предпочтение отдается гуманизации и гуманитаризации в учебном процессе. В потоке быстро сменяющих друг друга трендов и новых технологий, огромного количества информации и отвлекающих факторов, внимание и концентрация учеников в момент получения ими базовых знаний могут быть рассеяны, не сфокусированы должным образом. С этим явлением можно бороться проверенными методами традиционного преподавания, но более плодотворным будет такое отношение, когда преподаватель воспринимает веяние нового времени как фактор положительного влияния, относясь к обучению, не как к заученному шаблону, но как к постоянно меняющемуся и способному серьезно 
заинтересовать умы подрастающего поколения, полю созидательной деятельности.

Для этой цели предпримем попытку рассмотреть понятие «эдьютейнмент» в фокусе современной технологии развития творческого потенциала личности через игровое развлечение в системе общего среднего образования [1, с. 273]. Термин представляет собой гибридное понятие английского происхождения «Edutainment», образованное путем слияния двух слов: «еducation» - обучение и «entertainment»- развлечение [2, с. 67].

Н.А. Кобзева предлагает следующее определение: «Эдьютейнмент это технология обучения, рассматриваемая как совокупность современных технических и дидактических средств обучения, которая основана на концепции обучения через развлечение, смысл которой заключается в том, что знания должны передаваться в понятной, простой и интересной форме, а также в комфортных условиях» [3, с. 193].

Эксперимент. Данная технология обучения специфична и обусловлена наличием следующих признаков:

1. Игровой подход: благодаря универсальности игры происходит эффективный процесс обучения вне зависимости от возраста.

2. Акцент на увлечение, где необходимым является непосредственный интерес обучающегося, который приводит к развитию новых навыков и накоплению знаний.

3. Акцент на развлечение, которое выступает основным мотивом и приводит к удовольствию, одновременно формируя стойкий интерес к процессу обучения, снимает психологическую нагрузку от процесса образования.

4. Акцент на современность: при использовании актуальных возможностей современных технологий, таких как видео- и аудиоматериалы, дидактические игры, образовательные программы в 
мультимедийном формате и многие другие средства, достигается максимальная вовлеченность обучающихся в образовательный процесс.

Следовательно, эдьютейнмент - особый тип обучения, который основывается на развлечении и формировании первичного интереса к предмету с получением удовольствия от процесса обучения и стойким интересом к процессу обучения [4, с. 63].

Таким образом, в данной технологии важнейшим качеством является новизна, а объект изучения должен мотивировать к насыщенному и эффективному обучению. Эдьютейнмент отличается от традиционного обучения тем, что здесь субъект является активным участником процесса обучения, следовательно, при взаимодействии активного субъекта и информативно-развлекающего объекта мы получаем необходимый опыт в совокупности со знаниями и эмоциями.

M.M. Зиновкина определила «креативное образование» как целенаправленное последовательное освоение учеником передаваемых ему методологий и опыта творческой деятельности с формированием собственного творческого опыта $[5$, с. 100]. Основное внимание концентрируется на развитии творческого воображения, фантазии, творческих способностей и других качеств, необходимых для саморазвития подрастающего индивидуума.

Согласно другой точке зрения, понятие «эдьютеймент» можно рассматривать в качестве особого типа обучения, который основывается на развлечении и формировании первичного интереса к предмету с получением удовольствия от процесса познания и стойким интересом к процессу обучения [6, с. 64].

Эдьютеймент на практике имеет как положительные, так и отрицательные стороны. Остановимся на них подробнее.

К числу положительных характеристик метода можно отнести развлекательный характер материала, его доступность для понимания, 
простоту изложения и наглядность объекта. Основной задачей эдьютеймента на любом из этапов обучения является расширение общего кругозора обучающихся, удовлетворение любопытства и интереса.

К числу отрицательных характеристик или недостатков можно отнести тот факт, что эдьютеймент не предназначен для изучения серьезных проблемных вопросов. Во время его применения ограничено решение педагогических задач фундаментального характера, формирование глубоких базовых знаний. Приобретение профессиональных навыков обучающимися также стоит под вопросом.

Возникновение эдьютеймента в системе школьного образования нельзя назвать стихийным. Он возник в результате потребности педагогики разнообразить деятельность обучающихся, заинтересовать их в продолжении процесса познания. Также одной из причин возникновения эдьютеймента в системе образования является увеличение объема и усложнение изучаемого материала.

Первым игровую деятельность, как педагогическую классифицировал Фридрих Фрёбель. В его понимании теория игры является основой теории педагогики. Выявив дидактические ракурсы игровой деятельности, он доказал, что игра облегчает учителю задачу обучения ребёнка. Например, при освоении представлений о форме, цвете, величине предметов помогает ученикам овладевать культурой движения. Кроме того, он доказал, что в основе инстинктов ребенка лежит стихия, а, значит, его внутренний мир. В занятиях физическими упражнениями и уроках по сельскохозяйственному труду с детьми ученый активно использовал приемы занимательной наглядности [7].

Впервые данное понятие было использовано еще в 1948 году в студии Уолта Диснея для обозначения формата захватывающего документального сериала. Но сегодня смысл термина немного другой. Эдьютейнмент - 
образование в развлекательном формате, «учись развлекаясь, развлекайся в процессе обучения» [8, с. 217].

Результаты и обсуждение. Современные взгляды на развитие игровых форм обучения показали, что с помощью игры могут решаться практически все педагогические задачи. Так, в современной педагогике широко применяются «методы активного обучения» [9, с. 5]. С.А. Рассадина также предполагала что, широкое распространение эдьютеймента имеет хорошие предпосылки, в частности, то, что с его помощью можно снять психологический барьер в процессе учения, который присутствует в сознании многих детей, в также сформировать их общекультурные компетенции в различных образовательных учреждениях вне зависимости от возраста обучающихся и их образовательных интересов [10, с. 499].

Если оценивать возникновение эдьютеймента с точки зрения потребности в педагогическом явлении, то можно отметить, что он возник как ответная реакция на строгую упорядоченность образовательного процесса, как движение к свободе творчества.

Некоторые исследователи предполагают, что в определенных обстоятельствах развлекательно-просветительская деятельность и практическая ситуативная проработка могут быть более эффективными, нежели традиционная подача теоретического материала [11, с. 408]. Поэтому, стоит отметить, что особенностью эдьютеймента является отражение модели поведения ситуативных норм, с которыми ребенок (школьник) может столкнуться (и, вероятнее всего, столкнется) во взрослом мире. В связи с этим рассматриваемая технология является одним из полезных инструментов для современного педагога, обучающего литературе, поскольку одними из основополагающих вопросов к каждому произведению являются следующие: «Чему нас хочет научить автор?», «Какой напрашивается вывод?», «В чем мораль?». Задавая подобные вопросы, педагог, вместе с учениками, стремится с большей точностью 
оценить и определить механизмы изменения поведения посредством повествования.

Обучающиеся средних и старших классов нередко оказываются в ситуации, когда в силу возрастных и психологических особенностей им требуется поддержка со стороны педагога, которая была бы направлена на формирование устойчивых нравственных и эстетических принципов. Важной частью современного образования является понимание происходящих в мире процессов, способность к их анализу и нравственной оценке [12, с. 179].

Таким образом, литературные произведения формируют ценности подрастающего поколения, их мировоззрение и позволяют анализировать собственное поведение на примерах поведения (ошибках и достижениях) героев. В частности, подобные цели и задачи напрямую ставятся при изучении сказок [13].

На уроках литературы применение эдьютеймента при обучении сказкам может быть организовано различными способами. Рассмотрим несколько из них:

- прослушивание сказок в формате аудиоматериала;

- просмотр презентаций с иллюстрациями из сказок, сопровождаемый прочтением сказок на аудионосителе;

- просмотр мультфильмов или фрагментов мультфильмов по теме сказок;

- проведение игры/квизов/викторин/брейнрингов и т.д. по содержанию сказок;

- соревнования - квесты в рамках классной комнаты;

- создание рисунок сказки при прочтении текста педагогом или презентации аудиоматериала на электронном носителем;

- театрализованная презентация фрагмента сказки при условии предварительной подготовки к такому типу задания; 
- работа с карточками;

- коллективные обсуждения прочитанного;

- создание собственных сказок на основании прочитанных (аналогий или возможно иных концовок) и т.д.

Основной причиной внедрения эдьютеймента в систему преподавания литературы, в целом, и сказок, в частности, является потребность ребенка в осуществлении развлекательно-игровой деятельности, стремление заинтересовать его в процессе познания, а не оттолкнуть от него.

Однако, важно помнить и о том, что принципы эдьютеймента, применяемые в школах, приобретают все большую популярность в ряде других учреждений, связанных с образовательной деятельностью. Все чаще к их числу относят не только университеты и школы, но и музеи, кафе, туристические агентства, библиотеки и многие другие. Нередко эдьютейнмент представляет собой мероприятие культурного характера (например, экскурсия, фестиваль, туристический слет, комильфо-вечер), в которое органично включается образовательная и деловая деятельность. Встречи проходят в неформальной обстановке и напоминают общение старых друзей, даже если люди видят друг друга впервые. Таким образом, участники эдьютейнмент-мероприятий получают возможность в свободной обстановке обсудить различные вопросы и получить нужную информацию $[14$, c. 22].

Сказки ассоциируются у детей с детством, игрой, поэтому процесс их изучения должен сопровождаться аналогичными методами преподавания. Иными словами, речь идет о влиянии социо-культурных изменений, находящих отражение и в господствующих педагогических принципах и стратегиях. Таким образом, эдьютеймент является актуальным феноменом современной культуры, отражающим усиление ее развлекательного начала, увеличения роли медиа и медиаразвлечений в жизни общества и оказывающих существенное воздействие на образовательных идей и 
познавательную деятельность человека современной цивилизации [15, с. 319].

Заключение. Таким образом, обучение на уроках литературы при работе над сказками по возможности должно быть сопряжено с понятием эдьютеймента, т.е. некой игровой методики, которая может быть представлена в различных форматах.

Внедрение эдьютеймента в процесс преподавание сказок может осуществляться различными способами. Это могут быть игры, квесты, наглядные пособия, аудиовизуальный материал и т.п. Выбор конкретного способа и метода ведения урока зависит от возрастных и индивидуальных потребностей обучающихся. В связи с этим все большую актуальность приобретает вопрос применения личностно-ориентированной технологии обучения.

\section{Литература}

1. Дьяконова О.О. Дидактический утилитаризм: эдьютейнмент как инновационное решение проблем образования взрослых // Вестник ТвГУ. Серия «Педагогика и психология». 2015. №3. С. 271-276.

2. Железнякова О.М., Дьяконова О.О. Сущность и содержание понятия «Эдьютейнмент» в отечественной и зарубежной педагогической науке // Вестник Высшей школы. Серия «Педагогика и психология». 2013. №2. C. 67-70.

3. Кобзева Н.A. Edutainment как современная технология обучения. Ярославский педагогический вестник. 2012, № 4, Том II (Психологопедагогические науки). С. 192-195.

4. Кармалова Е. Ю., Ханкеева А. А.. Эдьютейнмент: понятие, специфика, исследование потребности в нем целевой аудитории. Вестник Челябинского государственного университета. - 2016. № 7 (389). С. 6471. 
5. Утемов В.В., Зиновкина М.М., Горев П.М. Педагогика креативности: прикладной курс научного творчества. Учебное пособие. Киров: Межрегиональный центр инновационных технологий в образовании, $2013.212 \mathrm{c}$.

6. Сапух T. В. Применение технологии «эдьютейнмент» в образовательной среде университета / Т. В. Сапух // Вестник ТГПУ, 2016, № 8 (173). C. 30-34.

7. Мельникова М. Ю. Фребелевская система воспитания детей раннего и младшего дошкольного возраста [Электронный ресурс] // Открытый педагогический форум «Новая школа». URL: http://forum.schoolpress.ru/article/56/433 (Дата обращения: 07.07.2020).

8. Хангельдиева И. Г. Эдьютейнмент: от телевизионного формата до современных социальных и образовательных практик // Хангельдиева И. Г., Богданова Е. М. // Сб. науч. ст. по материалам Всерос. науч. конф. с междунар. участием «Культура и образование в современном обществе: стратегии развития и сохранения». Краснодар: ООО «Экоинвест», 2013. С. 206-218.

9. Зарукина Е. В., Логинова Н. А., Новик М. М. Активные методы обучения: рекомендации по разработке и применению: учеб.-метод. пособие. СПб. : СПбГИЭУ, 2010. 59 с.

10.Рассадина С.А. Культурологические основания концепции «edutainment» как стратегии формирования общекультурных компетенций в вузах негуманитарного профиля // Записки Горного института. 2016. Т.219. С. 498-503.

11. Moyer-Gusé E. Toward a theory of entertainment persuasion: Explaining the persuasive effects of entertainment-education messages. Communication Theory. 2008. № 18(3). C. 407-425. 
12.Цвык А.В. Нравственные основы международных отношений // Вестник Российского университета дружбы народов. Серия: Философия. 2014. № 2. С. 176-183.

13.Kirkman E., Hallsworth M. Early Edutainment: The Behavioral Scientist's Guide to Fairy Tales [Электронный pecypc] // The Behavioral Scientist. 2019. URL: https://behavioralscientist.org/the-behavioral-scientists-guideto-fairy-tales/ (Дата обращения: 23.10.2020).

14.Клецкий М. Е. Человек изобретающий // М. Е. Клецкий, С. В. Крузе, С. В. Пономарева // Справочник руководителя учреждения культуры. 2011. № 11. C. 20-30.

15.Беляков П.В. Эдьютейнмент в цифровой среде: социокультурный анализ технологий // Вестник РГГУ. Серия «История. Филология. Культурология. Востоковедение». 2018. № 8 (41). Ч. 2. С. 312-321. 